\title{
A INCLUSÃO DO ALUNO AUTISTA NA ESCOLA COMUM: DESAFIOS E POSSIBILIDADES
}

\section{A INCLUSION OF THE STUDENT IN THE COMMON SCHOOL: CHALLENGES AND POSSIBILITIES}

\author{
Silvani Carlotto ${ }^{1}$ \\ Marcia Regina de Assis Danelichem ${ }^{2}$ \\ Grasiele Camapum Billerbeck ${ }^{3}$
}

RESUMO: A inclusão do autista depende de vários fatores como escola, família, sociedade, mas também do conhecimento sobre autismo. Assim esta pesquisa objetiva investigar se existem possibilidades de inclusão de um aluno autista na sala de aula de escola Pública. Portanto, este é o foco do presente estudo: a inclusão de alunos com autismo na classe regular. Com estes dados, buscamos analisar as circunstâncias que esses alunos estabelecem com seus professores e colegas nas classes da rede regular de ensino. Assim, pretende-se avaliar como se processa a inclusão destes alunos na sala de aula comum, em que a maioria dos alunos, não apresenta tais necessidades. É visto que essa situação traz impactos em relação às possibilidades de interação, comunicação e construção de conhecimento desses alunos. O estudo está orientado para a repercussão dessas condições que implicam a não existência de um território comum, com consequências para a explicitação de ideias e o diálogo autêntico, principalmente porque escola e os professores estão despreparados para atender a estes alunos. A escola no transcorrer da sua história, se caracterizou pela visão onde a escolarização é privilégio de um grupo, nesse meio tempo foi criado uma exclusão que foi legitimada nas políticas e práticas educacionais da ordem social. A partir do processo de democratização da educação identificou-se está inclusão/exclusão, quando os sistemas de ensino estende o acesso, mas ainda continuam excluindo indivíduos e grupos considerados fora dos padrões normais da escola, como os alunos autistas.

Palavras-chave: Autismo. Escola. Professores.

\footnotetext{
${ }^{\mathrm{I}}$ Especialista em Educação Infantil e séries iniciais. Faculdade Invest de ciências e tecnologias. Cuiabá MT.CMEI Joana Mont serrat Spindola e Silva E-mail: Silvacarlotta@hotmai.com.

${ }^{2}$ Especialista em Educação Infantil. Faculdade Educacional da Lapa-PR CMEI Joana Mont serrat Espindola e Silva - Cuiabá MT. marcia.danelichen@gmail.com.

${ }^{3}$ Graduada em Pedagogia - Licenciatura. Faculdade Evangélica do Piauí (Instituto Educacional Sheknah - Cuiabá.
} 
ABSTRACT: The inclusion of the autistic depends on several factors such as school, family, society, but also knowledge about autism. Thus this research aims to investigate if there are possibilities of inclusion of an autistic student in the public school classroom. Therefore, this is the focus of the present study: the inclusion of students with autism in the regular class. With this research, we seek to analyze the circumstances that these students establish with their teachers and colleagues in the classes of the regular network of education. Thus, it is intended to evaluate how the insertion of these students is processed in the context of the common class, in which the majority of students do not present such needs. It is seen that this situation impacts on the possibilities of interaction, communication and knowledge construction of these students. The study is oriented to the repercussion of these conditions that imply the non existence of a common territory, with consequences for the explicitation of ideas and the authentic dialogue, mainly because school and teachers are unprepared to attend these students. The school in the course of its history, characterized by the vision where the schooling is the privilege of a group, in the meantime an exclusion was created that was legitimized in the policies and educational practices of the social order. From the process of democratization of education this inclusion / exclusion was identified, when the education systems extend access, but still continue to exclude individuals and groups considered outside normal school patterns, such as autistic students.

Keywords: Autism. School. Teachers.

INTRODUÇÃO

Hoje, a Educação busca compreender alguns Transtornos do Desenvolvimento como o Autismo, Síndrome de Down, TDAH, dentre outras que são bastante visíveis no âmbito escolar. Embora existam outras patologias, o profissional deve se atentar para que possa incluir seus alunos com deficiência nas suas aulas de maneira correta e adequada, possibilitando oportunidades de interação dentro e fora da escola.

Ao longo da história, as pessoas com deficiência e transtorno têm enfrentado situações adversas às suas realidades, seja pelo desconhecimento do que são essas deficiências, como era o caso dos temos remotos quanto pelo descaso nos tempos atuais, pois ainda hoje, falamos de respeito mútuo como algo que deve prevalecer e leis que assegurem os direitos e deveres, porém, a sociedade demonstra que ainda não está preparada para incluir, fazendo com que essas pessoas busquem tentativas de se adaptarem aos meios. 
A educação inclusiva está presente no nosso dia-a-dia, com o pressuposto de que toda criança tem direito à educação de qualidade. Portanto, a escola para incluir as crianças com necessidades especiais precisa estar preparada para corresponder a tais necessidades. Precisa se adequar aos novos alunos, proporcionando-lhes um ambiente acolhedor e instigador da aprendizagem. Ou seja, uma educação inclusiva se refere a uma educação para todos, não somente do ponto de vista de quantitativo, mas também na qualidade, possibilitando aos alunos a apropriação do conhecimento, a integração social o uso de seus direitos.

A escola para ser inclusiva precisa se adaptar a todos os alunos, não só ao especial, reestruturando sua organização escolar e pedagógica para que cada aluno faça parte da instituição, receba um atendimento especializado e de qualidade para que possa estudar e viver socialmente. Contudo, quando ocorre apenas o processo de integração ao aluno especial possibilita-se a inserção em uma sala de aula onde irá interagir com os demais, participando das aulas, cumprindo seu "dever" de aluno, mas a escola não muda a sua estrutura para que isso aconteça; simplesmente o aluno com necessidades especiais será tratado como igual a todas outras crianças. $O$ processo de inclusão vai além do de integração.

De acordo com Ainscow apud Sánchez (2005, p.15), "a educação inclusiva vai muito além de atender ao alunado com necessidades educacionais especiais, uma vez que supõe a melhoria das práticas educativas para todos os alunos e para o conjunto da escola”. Ou seja, a inclusão abrange a todos os alunos, proporcionando uma educação de qualidade. Promove uma reformulação no currículo e na capacitação dos professores, enquanto a integração visa apenas um individuo aquele que é "excluído" da sociedade.

A inclusão de pessoas com necessidades educacionais especiais é lei no âmbito nacional. A LDB, Lei no. 9.394 de 20 de dezembro de 1996 (BRASIL, I996), define no capítulo V que "a educação para alunos com deficiência deve ser oferecida preferencialmente na rede regular de ensino, assegurando aos mesmos currículos, métodos, técnicas, recursos educativos específicos para atender às suas necessidades”, dentre outros. 
Portanto, a escola para se tornar inclusiva deve se dispor a mudar seu currículo e ambiente, fazendo com que todos os alunos sejam beneficiados, mudando o seu paradigma educacional a fim de atingir toda a sociedade.

Diante de tal configuração, questiona-se: É possível incluir um aluno autista nas aulas regular? Para responder tal pergunta, a pesquisa tem como objetivo investigar as possibilidades de práticas pedagógicas inclusiva de alunos autistas nas aulas regulares.

O termo Autismo tem origem grega quer dizer "autós" ou "de si mesmo", foi empregado dentro da psiquiatria, para denominar comportamentos humanos que centralizam-se em si mesmo, ou seja, voltados para o próprio individuo. (ORRU, 2012, p.17). Os primeiros estudos e investigações cientificas sobre o autismo foram apresentados pelo Dr. Leo Kanner na década de 1940. Em seu estudo publicado em 1943, sob o nome de "distúrbio autístico do contato afetivo, Kanner concebeu o Autismo como um quadro de psicose, originado pela falta de amor parental, determinando um comportamento estranho na criança, uma incapacidade de estabelecer relações com outras pessoas, fuga da realidade, isolamento e um comportamento obsessivo. Paralelamente as pesquisas de Kanner, Hans Asperger no ano de 1944 também identificou em crianças alguns sintomas semelhantes, no entanto, desligado da teoria psicogênica de Kanner, Hans Aspeger levou outros pesquisadores anos mais tarde a investigar as características e os amplos espectros apresentados pelo autismo tendo como bases novas abordagens. Atualmente, o Autismo é considerado um distúrbio do desenvolvimento que se caracteriza por alterações presentes desde idade muito precoce, tipicamente antes dos três anos de idade, com impacto múltiplo e variável em áreas nobres do desenvolvimento humano como as áreas de comunicação, interação social e aprendizado (MELLO, 2007, p. 16).

No entanto, ainda faltam condições apropriadas que garantam a permanência deste aluno na escola, principalmente no que tange a formação dos profissionais para atuar com a escolarização destes estudantes. Na prática, o que se tem percebido é o pouco conhecimento sobre esta condição de deficiência. 


\section{METODOLOGIA}

A presente pesquisa é de natureza bibliográfica e de pesquisas, que se fundamenta numa abordagem qualitativa, com coleta de dados através de artigos encontrados na internet relacionada à família/escola, onde buscam conhecer a realidade social e material do processo de inclusão de alunos autistas no ensino regular.

Neste sentido, justificamos a pesquisa como descritiva, onde valoriza o processo e não apenas os resultados, haja vista que a problemática apresentada visa trazer uma reflexão sobre o papel do professor frente a temática da inclusão do aluno autista.

\section{I.o CARACTERÍSTICAS E VISÃO CONCEBIDA DO AUTISMO.}

O que é o autismo? A pesquisa feita no seguinte artigo da Universidade Federal de Rondônia nos revela que:

[...]O autismo é uma condição caracterizada pelo desenvolvimento acentuadamente anormal e prejudicado nas interações sociais, nas modalidades de comunicação e no comportamento (American Psychiatric Association [APA], 2013). Tais características variam na maneira como se manifestam e no grau de severidade, estando dificilmente presente da mesma maneira em mais de uma pessoa. Desde sua descoberta pelo médico austríaco Leo Kanner em 1943, este transtorno ou condição mental tem sido motivo de inúmeras discussões e controvérsias em relação ao seu diagnóstico, causas e tratamentos adequados. Sabe-se, por exemplo, que sua origem é determinada por fatores multicausais (Schwartzman, 20ria), mas não há respostas suficientes que os determinem, especificamente. No cenário científico, existem, por um lado, hipóteses de causas psicoafetivas, em que o autismo decorreria de impasses na constituição subjetiva do sujeito (Campanário \& Pinto, 20II; Rabello, 2004) ou de perturbações profundas na relação da criança com o meio (Hall, Nicholson, \& Adilof, 2006; Volk, Lurmann, Penfold, Hertz-Picciotto, \& McConnell, 2013). Por outro lado, existem hipóteses de causas neurobiológicas ou geneticamente determinadas, as quais priorizam proposições em que o autismo seria ocasionado por condições genéticas (Mecca et al., 20II), anormalidades cerebrais (Bolton, Griffiths, \& Pickles, 2002), alterações neuronais (Kooten et al., 2008; Wang et al., 2009) ou translocações cromossômicas (Tarelho \& Assumpção, 2007).[...]

Tais vertentes científicas, muitas contraditórias entre si, formam a complexa conjuntura na qual o autismo está inserido, contribuindo para que muitas questões 
continuem na obscuridade. Desta forma, tal como aponta Klin (2006), o autismo tem permanecido um conceito heterogêneo que inclui múltiplos sintomas e uma variedade de manifestações clínicas em uma amplitude de níveis de desenvolvimento e de funcionamento, ainda que tenha havido recente tentativa de delimitá-lo e de simplificá-lo, como feito pela APA (2013).

No que tange à educação, as práticas atualmente reconhecidas às pessoas com autismo atuam sob um enfoque comportamental, estruturado a partir dos sintomas desta condição (Bragin, 20II; Orrú, 2012). No entanto, quando considerada a partir de um enfoque histórico-cultural, a educação se torna um processo de aprendizagem que impulsiona o desenvolvimento humano (Vygotski, 200o). Neste sentido, de acordo com Saviani (20II), a educação escolar tem o papel de transmissão do conhecimento cultural da humanidade de forma sistemática, conceituando-o formalmente. Em relação à pessoa com deficiência - incluindo-se o autista -, por meio de situações dialógicas com significado cultural, e não com o foco na deficiência, é possível que o aluno com deficiência se aproprie do saber escolar e se humanize (Vygotski, 1997).

\section{I.I A ATUAÇÃO DO PROFESSOR EM SALA DE AULA}

A aprendizagem desde o nascimento de um ser humano é considerado essencial para fundamental o desenvolvimento do mesmo. Ao longo da vida vai adaptando sobre de saberes importantes, se incluindo no mundo da cultura e transformando-se e modificando o mundo através da participação do outro. Contudo isso a educação tem sido o meio onde o ser humano buscar o seu desenvolvimento na sociedade. Sendo assim a família onde cresce uma criança com as características do autismo, espera-se que possam incluí-lo em uma rede de escola onde tenha professores aptos a lidar com esse novo horizonte.

A criança com autismo, com a visão que temos, sabe-se que é uma pessoa que

sente diferente, aprende diferente, deseja diferente e pensa diferente. É importante de primeira mão disciplina-los e não mobiliza-los, lembrando que nem todos autistas são aprendentes iguais, o que funciona para um, pode não funcionar para outro, tudo isto depende da relação Pedagógica da escola com os pais. $O$ professor precisa descobrir quais habilidades - sociais e acadêmicas - seu aluno já possui e quais ele 
precisa adquirir. A partir daí escolher os materiais adequados. Sempre priorizando a comunicação e a socialização.

Quando nos referimos ao papel do professor neste artigo, pressupomos que se faz necessário uma intervenção mediatizada por parte deste, nesse sentido, o professor deixa de ser apenas um transmissor de conhecimentos para ser um orientador, que estimula o desenvolvimento e a aprendizagem a partir de interações construídas no envolvimento de toda a turma. Podemos dizer que a mediação "é processo de intervenção de um elemento intermediário numa relação; a relação deixa, então, de ser direta e passa a ser mediada por esse elemento" (OLIVEIRA, I997, p.26).

Com relação a sua participação na inclusão da criança com autismo em escolas de ensino comum, o professor tem um papel importante, pois é ele quem recebe e estabelece o primeiro contato com a criança, seja ele positivo ou negativo, dessa forma ele é um grande responsável por efetivar ou não o processo de inclusão, considerando que é seu dever criar possibilidades de desenvolvimento para todos, adequando sua metodologia as necessidades diversificadas de cada aluno.

Abordamos então alguns modos de trabalho onde professores já utilizam em sala de aula e possam utilizar:

- Atividades com um nível mínimo de atenção;

- Estimular a memória de curto prazo com palavras ou temas que se conectem com a vida afetiva e cotidiana do educando,

- Estimular o repertório verbal, mostrando a cada ação uma palavra e a cada palavra uma ação;

- Propor trabalhos que estimulem a discriminação visual;

- Propor trabalhos que estimulem a discriminação auditiva;

- Executar uma atividade de cada vez;

- Relacionar a atividade à vida cotidiana e afetiva do aprendente.

É importante estimular o aluno autista nas seguintes atividades em sala de aula:

- Perseverança na conclusão de trabalhos; 
- Capacidade para lidar com os erros;

- Capacidade para lidar com frustrações;

- Habilidade para superar desafios e reveses;

- Afetividade;

- Trabalho em equipe.

Entendemos que para obter um bom resultado e relacionamento desta criança com o Professor, nem sempre depende somente da escola ou pedagogo, mas da ajuda dos pais, oque é essencial neste momento. É muito importante que ele tenha sensibilidade e serenidade para promover em sala de aula a consciência de atos inclusivos, buscando contribuir, dessa forma, no desenvolvimento e aprendizagem.

Temos observado na realidade educacional, que a formação de professores não oferece uma base sólida nos aspectos teóricos e práticos, de modo, que poucos professores possuem uma formação básica centrada nos aspectos inclusivos ou específica para o autismo, isso implica na falta de compreensão acerca das necessidades diferenciadas e conhecimentos necessários para ensinar a criança com autismo. Além de estudar e analisar o desenvolvimento da criança com autismo, o professor tem a incumbência de tornar a sala de aula um ambiente inclusivo, possibilitando às crianças o conhecimento das diferenças e o incentivo para que elas desenvolvam a solidariedade.

O professor necessita obter com a criança a autoconfiança e a independência, pois são características ausentes em sua personalidade. Para o professor também implica a responsabilidade de desenvolver atividades de acordo com o nível de conhecimento da criança, para que possa desempenhar as atividades de forma correta, surgindo então novos aprendizados e o avanço no desenvolvimento de atividades escolares.

\subsection{CONSIDERAÇÕES FINAIS}

À frente do que foi buscado e avaliado, é possível compreender que é essencial tornar acessível à entrada e continuidade de crianças com autismo em escolas de ensino regular, no entanto, não é um trabalho fácil tornar uma escola inclusiva, é 
essencial que governo, escola e família trabalhem juntos á favor da oferta de educação de qualidade, com as devidas condições e possibilidades para o crescimento e aprendizagem.

Não podemos discursar sobre inclusão sem fazer referência ao processo de ensino - aprendizagem, já que a inclusão tem o desígnio de fornecer as mesmas condições a todos os alunos, visando o crescimento e aprendizagem dos mesmos.

Através desse trabalho, identificamos o papel do professor como mediador da inclusão, ou seja, ele cria situações que oportunizam esse processo, se aproximando e gerenciando conflitos de modo que se faça compreender que as diferenças são características de todos os alunos, independente de ser deficiente ou não.

Compreendemos também, que a falta de uma formação sólida voltada para os aspectos inclusivos, reflete negativamente na prática docente do professor, pois ele precisa, de forma contínua, estar em contato com novas informações no que se refere a sua atuação profissional. Notamos ainda, que apesar das dificuldades existentes, o processo de inclusão é sim possível, desde que haja comprometimento e envolvimento por parte do professor, uma boa formação pedagógica, além de apoio escolar e familiar.

Desta forma, abordou ao longo do trabalho a importância em conceder situações significativas que potencializem a conquista de habilidades cognitivas e sociais e a crescente autonomia no contexto da escola regular. Reconhecemos que bons resultados na inclusão de autistas são percebidos, quando os profissionais, respondem as necessidades de aprendizagem destes alunos, com as realizações de ações e estratégias inclusivas em todos os espaços da escola.

Ao longo da pesquisa foi possível Compreender que as leis servem para assegurar o direito dos alunos, o acesso à educação e a aprendizagem, no entanto, muitas vezes não são garantidas na prática nas escolas comuns do ensino regular. $\mathrm{Na}$ prática escolar observa-se que a inclusão acontece por meio de práticas integracionistas do aluno no ambiente educacional.

Percebe-se pouca ou nenhuma qualificação dos docentes entrevistados, para atender as necessidades dos alunos com autismo ou necessidades educacionais especiais. A qualificação profissional continuada é um dos fatores essenciais para o 
entendimento do universo do espectro autista. As escolas precisam ofertar cursos todos os anos para as docentes, sobre a inclusão e tudo que ela envolve, a fim de preparar os profissionais para o que pode ocorrer em sala de aula, além de fortalecer o aprendizado contínuo.

É essencial o auxílio e apoio da família, da equipe pedagógica no processo de aprendizagem, bem como a realização de adaptação no currículo e atividades. Observou-se na entrevista que com professores de aula especial, há pouco vínculo afetivo entre o aluno e o professor. Nesse sentido, os professores de aulas especiais precisam ser considerados em reuniões pedagógicas.

\section{REFERÊNCIAS}

CARVALHO, R. Salto para o futuro. Educação especial: Tendências atuais, 1999.

CUNHA, E. Autismo na escola: um jeito diferente de aprender, um jeito diferente de ensinar - idéias e práticas pedagógicas, 2013.

Vygotski, 1997

PEREIRA, E. (1999) - Autismo: O significado como processo central. Lisboa: Secretariado Nacional de Reabilitação.

PEREIRA, E. (1999) - Autismo: O significado como processo central. Lisboa: Secretariado Nacional de Reabilitação.

ROGÉ, B. (1998) - Educautisme, Infância (o-3 anos, 3-6 anos, 6-12 anos). CNEFEI e APPDA. Educautisme. Projeto Horizon.

FELICIO, V. C. O autismo e o professor: um saber que pode ajudar. Bauru, 2007. 